INTERGENERATIONAL TRANSMISSION AND DATING VIOLENCE VICTIMIZATION

\title{
INTERGENERATIONAL TRANSMISSION AND DATING VIOLENCE VICTIMIZATION: EVIDENCE FROM A SAMPLE OF FEMALE UNIVERSITY STUDENTS IN MANITOBA
}

\author{
DOUGLAS A. BROWNRIDGE \\ University of Manitoba
}

\begin{abstract}
Using a sample of 120 female students attending 3 universities in Manitoba, the influence of different modes of intergenerational transmission on women's experiences of physical assault and sexual coercion in dating relationships was examined. Dating violence victimization was common: $26.9 \%$ experienced physical assault, among whom $41 \%$ suffered injuries. In addition, $36.4 \%$ of the sample experienced sexual coercion. Intergenerational transmission played a role in women's dating violence victimization. The most important mode of intergenerational transmission was imitation, suggesting that witnessing inter-parental violence must be addressed to improve the developmental health of exposed children.
\end{abstract}

Research suggests that dating violence is a major social problem. For example, a recent study of 31 university samples in 16 countries found the prevalence of physical assault in dating relationships to range from $17 \%$ to $45 \%$ (Straus et al., 2004). Canada is no exception with prevalence rates of dating violence ranging from $25 \%$ to $45 \%$, largely depending upon the sample and time frame under examination (Barnes, Greenwood, \& Sommer, 1991; DeKeseredy \& Kelly, 1993; Pedersen \& Thomas, 1992; Sharpe \& Taylor, 1999). The high rate of dating violence suggests that more work needs to be done to understand its occurrence so that we can prevent what may become a lifetime pattern of violent behaviour.

One of the most popular and commonly studied explanations for dating violence is its intergenerational transmission (Jackson, 1999). According to this approach, which is based on social learning theory (Bandura, 1977), childhood exposure to violence in the family of origin will lead to an increased likelihood of perpetrating and/or experiencing violence in intimate relationships.

Although exposure to violence in one's family of origin is a strong correlate of subsequent violence, the majority of exposed children do not suffer this fate (Kaufman \& Zigler, 1987; Widom, 1989). In an attempt to understand the process through which violence is intergenerationally transmitted, many researchers have examined factors that may mediate intergenerational transmission. However, Hines and Saudino (2002) have argued that these mediators do not explain the fact that intergenerational transmission can lead to both perpetration and victimization. Indeed, research suggests that the intergenerational transmission of victimization may be more salient than the intergenerational transmission of perpetration. In a study of married and cohabiting couples in the United States, Cappell and Heiner (1990) concluded that "contrary to popular belief, knowing whether aggressive relations were present in the family of origin will be more useful in 
predicting whether the respondent is the target of aggression than in predicting whether the respondent is the perpetrator" (pp. 149-150). With respect to dating violence, several studies have shown that individuals who were exposed to family of origin violence in childhood are more likely to be victims of violence in a dating relationship (DeMaris, 1987; Gwartney-Gibbs, Stockard, \& Bohmer, 1987; Kalmuss, 1984; Laner \& Thompson, 1982; Malik, Sorenson, \& Aneshensel, 1997; Marshall \& Rose, 1988; O’Keefe, 1998; Sigelman, Berry, \& Wiles, 1984; Simonelli, Mullis, Elliott, \& Pierce, 2002; Stets \& PirogGood, 1987).

One way to shed light on this phenomenon is to compare different modes or ways through which violence can be transmitted (Kalmuss, 1984), such as modelling parental behaviour. In the dating violence literature, Simons, Lin, and Gordon (1998) have applied an understanding of different modes of intergenerational transmission to men's dating violence perpetration. However, an analysis comparing different modes for the intergenerational transmission of dating violence victimization was not found in the literature.

In a review of risk factors associated with perpetration and victimization, Riggs, Caulfield, and Street (2000) identified both overlapping and unique factors that place men at risk of perpetrating violence and women at risk of experiencing violence. Given the well-established relationship between childhood exposure to intrafamilial violence and dating violence victimization, as well as the knowledge that predictors of perpetration and victimization are not necessarily the same, the absence of an examination of different modes for the intergenerational transmission of dating violence victimization is a gap in the literature. Hence, the purposes of the present investigation were (a) to apply the theoretical framework of Simons et al. (1998) to the exploration of connections between parental behaviours and women's dating violence victimization and (b) to assess explanations for intergenerational transmission as they pertain to women's dating violence victimization.

\section{EXPLANATIONS FOR THE INTERGENERATIONAL TRANSMISSION OF DATING VIOLENCE}

\section{Four Potential Modes of Transmission}

Simons et al. (1998) identified four modes through which parental behaviour could increase the risk for perpetration of dating violence. What follows will outline how each mode may lead to perpetration as well as extrapolate what this may imply for understanding the intergenerational transmission of victimization.

Imitation explanation. The first potential mode of transmission is imitation. Essentially, children who witness violence between their parents learn that violence is normal in romantic relationships. As a result, through imitation of their parents they will be more likely to have violent interactions in their intimate relationships. It is possible, then, that imitation of violence in romantic relationships applies not only to perpetration but also to victimization. That is to say, if children grow up witnessing inter-parental violence, they will be more likely than those who do not witness inter-parental violence to tolerate partner violence (Gwartney-Gibbs et al., 1987) and, hence, be victims of partner violence.

Legitimation explanation. A second potential mode of transmission is through legitimation. This mode of transmission is broader in the sense that it is not limited to the imitation of inter-parental violence. Rather, from this perspective children who are exposed to any form of family violence learn that violence is a legitimate part of loving relationships. According to Simons et al. (1998), this explanation suggests that exposure to cor- 
poral punishment also places individuals at risk for dating violence. Given that this explanation includes any form of family violence, it would seem reasonable to also posit a connection between child sexual abuse in the family of origin and subsequent dating violence. These factors may also lead to dating violence victimization. That is, having witnessed inter-parental violence, having experienced corporal punishment at the hands of a parent, and/or having experienced intrafamilial child sexual abuse may legitimate not only the use of violence but also the experience of violence in later romantic relationships.

Observational learning explanation. A third possible mode of transmission is through observational learning. Simons et al. (1998) argue that the imitation and legitimation explanations lack a key insight provided by social learning theory. According to the interpretation of social learning theory by Simons et al., behaviour will be repeated only if it is perceived as having a positive effect. Noting that corporal punishment often results in a temporary alteration in behaviour, Simons et al. reason that corporal punishment is the only form of family violence through which children will learn that violence can be an effective tool for achieving behavioural change in family relationships. In this explanation, then, it is primarily children who have been victims of corporal punishment in their family of origin who will be at risk for transmission of violence. In terms of victimization, these individuals may be the only ones who view violence as rewarding and, hence, acceptable. An application of the observational learning explanation therefore suggests that only individuals who experienced corporal punishment will be at increased risk for victimization, given that they see value in the use of violence as a means to an end.

Criminological perspective. Simons et al. (1998) also identify a "criminological perspective" which suggests that violent parents transmit a general pattern of antisocial behaviour to their children. According to Simons et al., parents who have antisocial tendencies are more likely to be ineffective. Ineffective parents, such as those who are not involved or supportive, place their children at risk for dating violence by increasing the likelihood that they will develop antisocial tendencies. The children's antisocial tendencies persist throughout the lifespan, thereby affecting the probability that they will engage in dating violence. Thus, according to this perspective it is ineffective parenting and, as a result, the extent to which children develop an antisocial personality that account for the intergenerational transmission of dating violence. In terms of dating violence victimization, it is possible that having an antisocial personality predicts not only the perpetration but also the experience of dating violence. In addition to predicting dating violence perpetration, characteristics related to antisocial personality disorder, such as being irresponsible and impulsive and having poor social relationships, may contribute to an increased likelihood of being a victim of assault.

\section{Evidence for the Explanations}

Two studies of dating violence that test indicators linked to all of the aforementioned explanations were identified. Using data from a prospective sample of 113 adolescent males, Simons et al. (1998) tested the impact of corporal punishment, martial violence, involved and supportive parenting, and delinquent behaviour on perpetration of dating violence. They found that corporal punishment had a direct impact on dating violence perpetration. Ineffective parenting influenced dating violence perpetration indirectly through delinquent behaviour. Marital violence, however, did not have an impact on the perpetration of dating violence. These findings suggested support for both the criminological and observational learning perspectives. 
Lavoie et al. (2002) investigated the impact of witnessing inter-parental violence, abusive parenting, laxness of parental monitoring, familial adversity, and antisocial behaviour on male perpetration of dating violence. Using data based on a longitudinal sample of 717 boys in Montreal, these researchers found that witnessing inter-parental conflict and familial adversity did not affect boys' perpetration of dating violence. On the other hand, abusive parenting, low parental monitoring, and antisocial behaviour were all linked to violence perpetrated by boys against dating partners. Like those of Simons et al. (1998), these results suggested support for both the criminological and observational learning perspectives.

The research of Simons et al. (1998) and Lavoie et al. (2002) advanced our knowledge of how parental behaviours influence men's perpetration of dating violence-although not, as previously noted, of how the explanations operate in the prediction of female victimization. In addition, some other aspects of their studies limit our knowledge of this phenomenon.

First, the indicator used by Simons et al. (1998) to measure boys' witnessing of violence was based on parents' reports of violence they experienced within the preceding month. Some boys who witnessed violence may have been misclassified as a result of the short time frame; furthermore, it was not possible with this indicator to determine whether the child actually witnessed inter-parental violence. Second, although the key to the criminological explanation is the development of an antisocial personality, both studies employed delinquent behaviour, and Simons et al. also included substance use or abuse, to measure antisocial behaviour. Of course, Antisocial Personality Disorder encompasses more than delinquent behaviour (American Psychiatric Association, 1994); thus, it would have been more informative to have had an actual measure of antisocial personality. Third, the study by Simons et al. (1998) was limited to physical violence. In her review of the extant literature, Jackson (1999) noted that the vast majority of research investigates only physical violence and that this leads to a "myopic view of dating violence" (p. 235). Moreover, the measure of physical violence employed by Simons et al. (1998) was based on one question that asked boys how often in the previous year they had hit, pushed, grabbed, or shoved a girlfriend. Jackson (1999) noted that socially desirable responding may explain the consistent finding in the research that women report higher rates of dating violence perpetration than do men. Restricting the measure of violence to only one item may have further limited boys' disclosure of dating violence perpetration since there is reason to believe that multiple items elicit higher disclosure rates (Smith, 1994). Although Lavoie et al. (2002) included both physical and psychological violence they did not include an analysis of sexual coercion as a form of dating violence, which may be particularly salient in dating relationships (DeKeseredy \& Kelly, 1993; Forbes \& Adams-Curtis, 2001). Finally, neither study included child sexual abuse, which may have an impact on dating violence, as an indicator of violence in the family of origin. Indeed, child sexual abuse has been linked to adult sexual perpetration (Romano \& De Luca, 1997) and victimization (Koss \& Dinero, 1989).

\section{MATERIALS AND METHODS}

\section{Sample}

The data for this research were collected between the spring of 2002 and early 2003 from university students at the Manitoba sites of the International Dating Violence (IDV) study (Straus et al., 2004). The data-gathering procedures were approved by ethics review 
boards of the University of Manitoba, the University of Winnipeg, and Brandon University, the three main universities in the province of Manitoba. One class from each university was selected on a convenience basis for administration of the IDV questionnaire. The purpose and voluntary nature of the survey were communicated orally and in writing prior to the start of the survey. Participants were assured of their anonymity and confidentiality, provided with a debriefing form that included contact information for local family violence services, and given the contact information of the author to allow them to obtain feedback.

The focus of this investigation was on unmarried women 18 years of age or older who had ever been in a dating relationship that lasted one month or more. Only a small portion of the sampled women (11.0\%) indicated that their relationship had ended more than one year prior to the survey. A comparison of both physical assault and sexual coercion by time since the most recent dating relationship ended yielded no significant differences. Since those whose dating relationships were not recent (ending more than one year prior to the date of survey administration) did recall and report violence having occurred in these relationships, the decision was made to retain these cases. This ensured that the prevalence rates were a more adequate reflection of all women in the sample who had experienced dating violence.

Nearly all of the women $(90 \%)$ indicated that their current or most recent relationship was one that involved dating or being engaged. Ten percent of women indicated that they were married and were excluded to avoid confounding dating violence with marital violence. The completed questionnaires were scanned for questionable response patterns such as reporting an implausibly high number of severe assaults or injuries (e.g., respondent had a broken bone from an attack 10 or more times in the previous year) and inconsistent responses (e.g., respondent reported being injured but did not report having been assaulted by a partner). Six percent of the participants had questionable response patterns and were excluded from the study. The exclusion of males, those who were married, and participants with questionable response patterns reduced the sample from 176 to 120 students. ${ }^{1}$

Most (67.2\%) of the women were within their first 2 years of university, with a median age category of 20 years. The vast majority (79.3\%) of the women were Caucasian. A sizeable minority of students (12.6\%) reported being of Aboriginal or Métis ancestry. Women of Asian and African ancestry constituted a small portion of the sample $(7.2 \%$ and $0.9 \%$, respectively). The women's socioeconomic background was generally middle-class with mothers and fathers having a high school diploma or some post-secondary school as the median education category and a median annual family income of $\$ 55,000-\$ 64,999$. Fourteen percent of the women reported living with/having lived with their dating partners. Research shows cohabitation status to be a risk marker for partner violence (Brownridge, 2004). To ensure that cohabitation status did not confound the results, this variable was included in the analyses. The vast majority (71.6\%) of relationships had lasted 6 months or more with sexual relations taking place between most (82.5\%) of the couples. Well over half of the sample (60.2\%) indicated that the relationship was current when the survey was administered.

\section{Measurement}

Independent variables. Cohabitation status was derived from a question that asked respondents with whom they lived. A woman who reported living with her dating partner or having lived with her dating partner prior to the relationship ending was coded as cohabiting. The remainder of the independent variables were derived from the Personal and 
Relationships Profile (PRP) (Straus, Hamby, Boney-McCoy, \& Sugarman, 1999). The PRP is an instrument designed to provide a profile of scores on individual- and relationshiplevel constructs that may be associated with partner violence. Each item in the PRP was measured on a four-point Likert scale ranging from strongly disagree to strongly agree. The scale scores were obtained by summing the items in the scale. ${ }^{2}$ Straus and Mouradian (1999) report that all of the PRP scales have at least adequate reliability when used on student samples.

Witnessing inter-parental violence was derived from the extent of the respondent's agreement with the statement "When I was a kid, I saw my mother or father kick, punch, or beat up their partner." Women who agreed or strongly agreed with this item were coded as having witnessed inter-parental violence.

Corporal punishment was measured by the extent of the respondent's agreement with the statement "I was spanked or hit a lot by my mother or father under the age of 12." Women who agreed or strongly agreed with this item were coded as having experienced corporal punishment.

Child sexual abuse was measured with the following two items from the sexual abuse history scale of the PRP: "Before I was 18, an adult in my family made me look at or touch their private parts (sex organs), or looked at or touched mine"; "Before I was 18, an adult in my family had sex with me (vaginal, anal, or oral)." The child sexual abuse scale scores ranged from 2 to 6 with a mean of 2.3. As Cappell and Heiner (1990) have noted, "the theory of intergenerational transmission of aggression requires a statistical association between the presence of aggression in the respondent's family of origin and some form of aggressive relations in the respondent's current family" (p. 139). Thus, the decision was made to use the subscale that measures child sexual abuse by an adult within the family to isolate potential intergenerational transmission within the family. For the purposes of the descriptive analyses, the scale was dichotomized, with women having a score of 4 or higher being classified as having been sexually abused. Since only two items from the sexual assault history scale were used, the reliability of the modified scale was low $(\alpha=.49)$. Schmitt (1996) has stated that low reliability should not preclude use of a measure "when a measure has other desirable properties, such as meaningful content coverage of some domain and reasonable unidimensionality" (pp. 351-352). A factor analysis of the modified scale resulted in a unidimensional solution, suggesting the appropriateness of its use.

Ineffective parenting was measured with the neglect history scale of the PRP. ${ }^{3}$ This eight-item scale measures unfulfilled cognitive (e.g., "My parents did not help me to do my best in school"), educational (e.g., "My parents did not care if I got into trouble in school"), emotional (e.g., "My parents did not comfort me when I was upset"), and physical needs (e.g., "My parents did not keep me clean") in the respondent's family of origin. The neglect history scale scores ranged from 8 to 26 with a mean of 12.5 .

Antisocial personality was measured with the antisocial personality scale of the PRP. This nine-item scale measures antisocial personality features derived from the DSM-IV (American Psychiatric Association, 1994), including irresponsibility (e.g., "I often do things that are against the law"), general hostility (e.g., "I don't feel sorry when I hurt someone"), impulsivity (e.g., "I often do things that other people think are dangerous"), and poor social relationships (e.g., "I don't think about how what I do will affect other people"). The antisocial personality scale scores ranged from 9 to 25 with a mean of 14.9.

Social desirability was measured with the social desirability scale of the PRP. In their analysis of the PRP, Straus and Mouradian (1999) found that social desirability poses a 
threat to validity for most of the scales on the PRP and concluded that social desirability "must be controlled to avoid erroneous results" (p. 10). This 13-item scale measures the extent to which respondents avoid disclosing undesirable behaviour. Although undesirable, the items in the scale are true of almost everyone. The greater the number of items the respondent denies, the less likely the respondent is to report other forms of undesirable behaviour such as criminal acts. Scores on the social desirability scale ranged from 22 to 44 with a mean of 32.9 .

Dependent variables. Physical assault, sexual coercion, and injury were measured with the revised Conflict Tactics Scales (CTS2) (Straus, Hamby, Boney-McCoy, \& Sugarman, 1996). The original CTS have been used widely and have proven to be reliable and valid (Archer, 1999; Straus, 1990). The physical assault portion of the CTS2 contains 11 items that can be divided into minor physical assault and severe physical assault subscales. Minor physical assault includes the following: being pushed, shoved, grabbed, or slapped; having something thrown at the respondent that could hurt; and having one's arm or hair twisted. Severe physical assault includes being punched or hit with something that could hurt; kicked; choked, slammed against a wall; beaten up; burned or scaled; and having a knife or gun used against the respondent.

Sexual coercion was measured with seven items from the CTS2 that are designed to measure acts to coerce a partner to engage in unwanted sexual activity. The minor sexual coercion items include being made to have sex without a condom, insistence on sex when the woman did not want to (without the use of physical force), and insistence on oral or anal sex (without the use of physical force). The severe sexual coercion items include being threatened into having oral or anal sex; being threatened into having sex; being forced (by being hit, by being held down, or through the use of a weapon) to have oral or anal sex; and being forced (by being hit, by being held down, or through the use of a weapon) to have sex. The severe sexual coercion items are consistent with the definition of sexual assault in section 273.1 of the Canadian Criminal Code (Johnson, 1996).

Injury was measured with six items from the CTS2 designed to assess the extent to which victims were injured. Minor injury includes feeling physical pain the day after a fight and having a sprain, bruise, or cut after a fight. Severe injury includes having a broken bone from a fight, needing to see a doctor because of a fight, going to see a doctor because of a fight, and passing out from being hit on the head during a fight.

The physical assault, sexual coercion, and injury scores were dichotomized to obtain a prevalence score. Since most of the acts on the overall scales are typically minor, to avoid redundancy only the overall scale and severe subscale are reported in the present study.

\section{Methods of Analysis}

The analysis was conducted in two stages. The first stage consisted of descriptive analyses in which bivariate relationships were examined using cross-tabulations with chi square tests of significance. These analyses were conducted to document the prevalence and incidence of physical assault, sexual coercion, and injury. As well, bivariate relationships between the independent variables and physical assault and sexual coercion were examined.

In the second stage, more elaborate analyses were conducted using multivariate statistical techniques. The first set of multivariate analyses was conducted with logistic regression. Logistic regression is an appropriate technique for predicting a dichotomous dependent variable from a set of independent variables. This technique also has a very simple 
interpretation. For a given variable it simply provides a ratio of the odds of violence occurring. If the value of the odds is greater than 1 the variable is positively related to the dependent variable. If it is less than 1 the variable is negatively related to the dependent variable. These analyses allow an assessment of the impact of the independent variables and estimation of the extent to which the model accounts for physical assault and sexual coercion experienced by the sample of dating women. One limitation of logistic regression, however, is that it cannot determine specific pathways through which variables influence violence. Logistic regression does not differentiate exogenous from endogenous variables nor does it allow the determination of direct and indirect effects. To refine the analysis of modes of transmission, the logistic regression analyses were supplemented with a second set of multivariate analyses using LISREL $8.30 .^{4}$

\section{RESULTS}

\section{Descriptive Analyses}

\section{TABLE 1}

Prevalence and Incidence Statistics on the CTS2 for Overall and Severe Levels of Violence and Injury

\begin{tabular}{|c|c|c|}
\hline Scale & Overall & Severe \\
\hline \multicolumn{3}{|l|}{ Physical assault } \\
\hline Lifetime prevalence $(\%)$ & 26.9 & 10.3 \\
\hline Annual prevalence $(\%)$ & 24.1 & 8.4 \\
\hline Annual incidence (mean) & 11.0 & 4.9 \\
\hline$(\mathrm{SD})$ & 9.6 & 7.2 \\
\hline \multicolumn{3}{|l|}{ Injury } \\
\hline Lifetime prevalence (\%) & 41.4 & 6.9 \\
\hline Annual prevalence $(\%)$ & 34.5 & 6.9 \\
\hline Annual incidence (mean) & 7.8 & 2.0 \\
\hline$(\mathrm{SD})$ & 9.6 & 1.4 \\
\hline \multicolumn{3}{|l|}{ Sexual coercion } \\
\hline Lifetime prevalence (\%) & 36.4 & 4.7 \\
\hline Annual prevalence $(\%)$ & 32.7 & 4.7 \\
\hline Annual incidence (mean) & 15.7 & 2.8 \\
\hline (SD) & 13.9 & 1.1 \\
\hline
\end{tabular}

Prevalence and incidence of violence and injury. Table 1 contains the prevalence and incidence statistics on the CTS2 for overall and severe levels of violence and injury. ${ }^{5}$ The results in Table 1 show that $26.9 \%$ of the sampled women had ever experienced physical assault by a dating partner. Most of these women had experienced this form of dating violence within the year preceding the survey, with an annual prevalence of $24.1 \%$. Within the year prior to the survey, victims reported having experienced physical assault on average almost once per month. A similar pattern emerges with respect to severe physical assault, with $10.3 \%$ of women reporting having experienced severe physical assault. Among the $8.4 \%$ of women who reported severe physical assault having occurred in the year prior to the study, this happened on average 4.9 times. 
Within the group of victims of physical assault, $41.4 \%$ reported having ever suffered an injury and $34.5 \%$ reported that this had occurred in the year preceding the survey. Victims were injured an average of 7.8 times in the year prior to the survey. Severe injuries were suffered by $6.9 \%$ of victims, occurring on average two times in the year prior to the survey.

Over one third $(36.4 \%)$ of the sampled women reported having ever experienced sexual coercion by a dating partner. For most of these women, sexual coercion by a date happened in the year preceding the survey, occurring on average more than once per month. Most of the sexual coercion is minor, but $4.7 \%$ of the women reported having experienced severe sexual coercion in the year prior to the survey.

TABLE 2

Lifetime Prevalence of Physical Assault and Sexual Coercion by Independent Variables (\%)



$* p \leq 0.10 ; * * p<0.05 ; * * *<0.01$ ( $p$ values refer to chi square tests of significance)

Independent variables by physical assault and sexual coercion. In the remaining analyses the prevalence data are employed to examine the occurrence of dating violence victimization. Table 2 contains the results of the cross-tabulations of the independent variables by physical assault and sexual coercion. Based on the analysis of bivariate relationships shown in Table 2, only one independent variable was significantly related to 
physical assault. Women who witnessed inter-parental violence were almost three times more likely to have experienced physical assault than women who did not witness physical violence between their parents. Of the sampled women who witnessed inter-parental violence, $60 \%$ experienced physical assault by a dating partner. The relationship between the remainder of the independent variables and physical assault were generally in the expected direction, but did not achieve statistical significance.

The results in Table 2 also show a strong relationship between witnessing interparental violence and experiencing sexual coercion by a dating partner. Of women who had witnessed inter-parental violence, $73.3 \%$ reported having been coerced into some sexual activity by a dating partner. Unlike physical assault, sexual coercion by a dating partner showed a significant relationship with several other independent variables. Women who had experienced corporal punishment were more than twice as likely as those who did not to have been coerced into sexual activity by a dating partner. The higher a woman's rating on both the history of neglect and antisocial personality scales, the more likely she was to be a victim of sexual coercion in a dating relationship. As well, women with high scores on the social desirability scale were significantly less likely to report experiencing sexual coercion by a dating partner.

\section{Multivariate Analyses}

\section{TABLE 3}

Logistic Regression on Lifetime Prevalence of Physical Assault and Sexual Coercion

\begin{tabular}{|c|c|c|}
\hline Covariates & $\begin{array}{c}\text { Physical Assault } \\
n=98 \\
\text { Odds Ratio }\end{array}$ & $\begin{array}{c}\text { Sexual Coercion } \\
\boldsymbol{n}=\mathbf{9 7} \\
\text { Odds Ratio }\end{array}$ \\
\hline \multicolumn{3}{|l|}{ Witnessed inter-parental violence } \\
\hline Yes & $7.893 * *$ & $13.880 * *$ \\
\hline No & 1.000 & 1.000 \\
\hline \multicolumn{3}{|l|}{ Experienced corporal punishment } \\
\hline Yes & 0.398 & 2.502 \\
\hline No & 1.000 & 1.000 \\
\hline Experienced child sexual abuse & 0.770 & $0.301 * *$ \\
\hline History of neglect & 1.063 & 1.077 \\
\hline Antisocial personality & $1.337 * *$ & $1.224^{*}$ \\
\hline \multicolumn{3}{|l|}{ Cohabiting } \\
\hline Yes & 2.345 & 1.183 \\
\hline No & 1.000 & 1.000 \\
\hline Social desirability & 1.063 & 0.943 \\
\hline Constant & $0.000 * *$ & 0.817 \\
\hline-2 Log likelihood & 97 & 104 \\
\hline$\chi^{2}$ & 14 & 24 \\
\hline Nagelkerke Pseudo- $\mathrm{R}^{2}$ & .198 & .294 \\
\hline
\end{tabular}


Logistic regression analyses. Table 3 provides the results of the logistic regressions on physical assault and sexual coercion. The Nagelkerke pseudo- $\mathrm{R}^{2}$ indicates that all of the variables in the models account for $19.8 \%$ of the variance in physical assault and $29.4 \%$ of the variance in sexual coercion. In other words, the intergenerational transmission variables included in the study were not the only factors linked to the sampled women's odds of dating violence victimization. Controlling for all other variables in the models, witnessing inter-parental violence was the variable that had by far the largest impact on the odds of both physical assault and sexual coercion. Having experienced corporal punishment, on the other hand, was not significantly linked to either physical assault or sexual coercion, though women who had experienced corporal punishment had $150 \%$ higher odds of sexual coercion. Having been sexually abused as a child was not significantly linked to physical assault, but was linked to sexual coercion. Controlling for all other variables in the model, child sexual abuse was negatively related to sexual coercion. Women who were sexually abused by an adult family member had $70 \%$ lower odds of being coerced into sexual activities by a dating partner than did women who were not victims of child sexual abuse. A history of childhood neglect was not significantly linked to either physical assault or sexual coercion. Antisocial personality was positively linked to both physical assault and sexual coercion. Each unit of increase on the antisocial personality scale was associated with a $34 \%$ increase in the odds of physical assault and a $22 \%$ increase in the odds of sexual coercion. Cohabiting was not significantly linked to either physical assault or sexual coercion. As well, the measure of social desirability did not have a significant impact on the odds of either physical assault or sexual coercion.

\section{FIGURE 1}

Path Model for Physical Assault

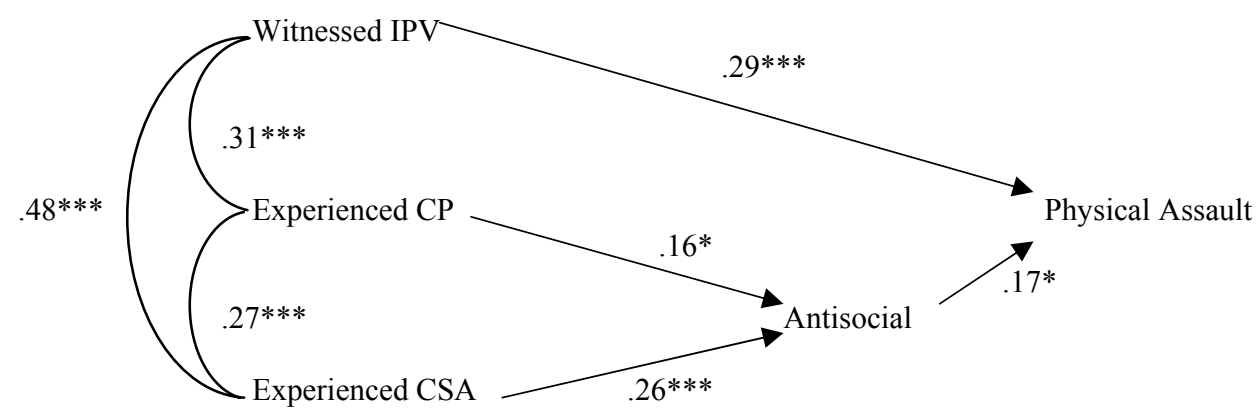

$* p \leq 0.10 ; * * * p<0.01$ ( $p$ values refer to two-tailed $t$ tests of significance); $n=120$

Path analyses. The path analyses were begun by running fully recursive models for physical assault and sexual coercion in which witnessing inter-parental violence, corporal punishment, child sexual abuse, and history of neglect were exogenous and antisocial personality, cohabiting, and social desirability were endogenous. The models were then modified on the basis of the significance of the paths, the modification indices, and the goodness of fit statistics to arrive at models that best fit the data. The best fitting model of physical assault is presented in Figure $1\left(A G F I=.94 ; \chi^{2}=3.67, d f=3\right.$; RMSEA $=.04 ;$ SRMR $=$ $.04)$. Figure 1 shows that the best-fitting model contained only four predictors of physical 
assault: witnessing inter-parental violence, experiencing corporal punishment, experiencing child sexual abuse, and antisocial personality. The only exogenous variable that had a significant direct effect on physical assault is having witnessed inter-parental violence. Experiencing corporal punishment and child sexual abuse had a significant positive association with antisocial personality which, in turn, was significantly positively associated with physical assault. However, the indirect effects of the corporal punishment $(I N=.03, t=1.29)$ and child sexual abuse $(I N=.04, t=1.57)$ variables did not reach statistical significance.

\section{FIGURE 2}

Path Model for Sexual Coercion

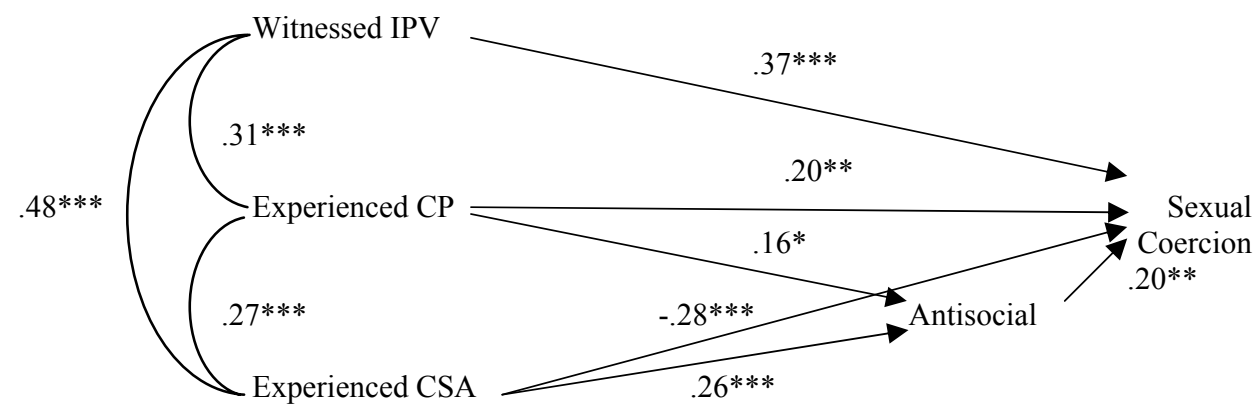

$* p \leq 0.10 ; * * p<0.05 ; * * * \mathrm{p}<0.01$ ( $p$ values refer to two-tailed $t$ tests of significance); $n=120$

The best fitting model of sexual coercion is presented in Figure 2 (AGFI $=.89 ; \chi^{2}=$ $2.17, d f=1 ;$ RMSEA $=.10$; SRMR $=.03$ ). The model in Figure 2 shows that the same four variables that influenced physical assault also influenced sexual coercion. In the case of sexual coercion, however, having witnessed inter-parental violence, having experienced corporal punishment, and having been sexually abused as a child all had a direct effect on sexual coercion. Witnessing inter-parental violence and having experienced corporal punishment had significant positive influences while child sexual abuse had a significant negative influence on women's experience of sexual coercion by a dating partner. The indirect effect of corporal punishment on sexual coercion through antisocial personality did not reach statistical significance $(I N=.03, t=1.40)$. However, the indirect effect of childhood sexual abuse by a family member on sexual coercion via antisocial personality was statistically significant $(I N=.05, t=1.78)$. Although having experienced child sexual abuse by an adult family member negatively affected sexual coercion by a dating partner, it positively influenced antisocial personality which, in turn, was positively associated with sexual coercion by a dating partner.

\section{DISCUSSION}

The prevalence rate of physical assault in the sample of female Manitoban university students, showing that approximately one woman in four was victimized, was within the range found in similar Canadian and international studies (Pedersen \& Thomas, 1992; Sharpe \& Taylor, 1999). Physical assaults by dating partners were quite common and 
frequent among the sampled women. The data also demonstrated that many of the victims of physical assault were injured and that the occurrence of injury was a frequent event. Victims experienced physical assault an average of 11 times per year and were injured an average of 7.8 times per year. This suggests that the majority of incidents of physical assault resulted in injury primarily involving a sprain, bruise, or cut following the conflict or physical pain the next day. This study found sexual coercion to be even more common than physical assault, which was consistent with the findings of other research (DeKeseredy \& Kelly, 1993). Moreover, sexual coercion occurred with greater frequency than physical assault. Clearly, sexual coercion was an important form of dating violence in this sample that was worthy of further analysis.

It is important at this juncture to reiterate that the main purpose of this study was to assess the explanations identified by Simons et al. (1998) as they pertain to women's dating violence victimization. As noted at the outset of this article, exposure to family of origin violence is a strong correlate of subsequent violence, but it is far from the only factor. This was evidenced by the intergenerational transmission variables explaining less than one third of the variance in women's experiences of dating violence. The focus of the present study on the intergenerational transmission of dating violence victimization should not be misinterpreted as overemphasizing the importance of these variables.

The descriptive and multivariate analyses painted an interesting portrait of how parental behaviours were related to the sampled women's dating violence victimization. Across all of the analyses, the variable that had by far the largest impact on both physical assault and sexual coercion was having witnessed inter-parental violence. Indeed, the majority of women who were victimized as children in the form of witnessing interparental violence were also victimized physically and sexually by a dating partner.

The results clearly provided the greatest support for the imitation explanation. This may seem surprising given that Simons et al. (1998) and Lavoie et al. (2002) did not find that witnessing inter-parental violence had an important influence on male perpetration of dating violence. However, gender differences regarding intergenerational transmission have been widely acknowledged in the literature. For example, Jackson (1999) reviews the research on gender effects of exposure to family of origin violence and concludes that the "findings are mixed but suggest that observing or experiencing violence in the family of origin impacts more significantly on men's use of violence in dating relationships than it does for women. There may, however, be more subtle and indirect effects on women, such as an impact on beliefs about staying in abusive relationships. These effects have not been examined in the literature and represent an area for further research" (p. 240). While exposure to family violence may not affect female perpetration to the same extent as it affects male perpetration, the present research demonstrated that it can strongly influence women's dating violence victimization.

Although there are inconsistencies in research on the role of same-sex models in dating violence victimization (Jankowski, Leitenberg, Henning, \& Coffey, 1999), O’Keefe (1998) writes that "the chances of imitation are greater when familiar, same-sex models perform sex-role appropriate behavior" (p. 40). The majority (70\%) of violence witnessed by children in Canada is violence against women, and children who witnessed violence against women tended to witness more severe violence (Dauvergne \& Johnson, 2001). In this context, then, it is possible to understand how witnessing inter-parental violence would strongly influence the male child's perpetration and the female child's experience of physical assault by a dating partner. The results of the present study further showed that witnessing inter-parental violence had an even stronger influence on women's experience 
of sexual coercion than it did on their experience of physical assault. Thus, while the modelling may be sex-role-specific, in this case it appeared to have been generalized to non-physically assaultive forms of victimization by a dating partner.

The results of the analyses also showed limited support for the criminological explanation. At the descriptive level of analysis, parental neglect was significantly related to sexual coercion but not physical assault. The former relationship disappeared when other variables in the models were controlled for in the logistic regression analysis. The path analyses did not find neglect to have a significant influence on antisocial personality. Rather, experiencing corporal punishment and child sexual abuse were the only significant influences on antisocial personality. The failure of neglect to be the key influence on antisocial personality was contrary to the expectations of the criminological perspective and the findings of Simons et al. (1998) and Lavoie et al. (2002). It is possible that this result was due to the focus on women rather than men in the present study. As noted above, men and women seem to be affected differently by exposure to family of origin violence. It is also possible that these findings could in part be due to measuring antisocial personality rather than delinquent behaviour. Children who were neglected may be more prone to delinquent behaviour to obtain things that they cannot otherwise acquire at home such as possessions and attention. This does not necessarily require an antisocial personality. As well, Lavoie et al. (2002) note that the impact of parental monitoring may be inflated in their sample, which was restricted to boys of lower socioeconomic status. In any case, in terms of dating violence victimization, antisocial personality was clearly the second most important variable placing the sampled women at increased risk for both physical assault and sexual coercion. Despite the finding that neglect was insignificant, intergenerational transmission appeared to play a role, particularly in terms of understanding the influence of antisocial personality on sexual coercion.

It is interesting that childhood sexual abuse was not a significant predictor of physical assault and, in fact, did not positively affect women's reports of physical assault and sexual coercion. The multivariate analyses revealed that, holding all other variables constant, child sexual abuse actually reduced the sampled women's likelihood of experiencing sexual coercion by a dating partner. According to the path analysis, however, victims of child sexual abuse who developed an antisocial personality faced an elevated risk of experiencing sexual coercion by a dating partner. Thus, the criminological explanation was supported, but only to the extent that it directed our attention to the importance of antisocial personality, and its attendant parental influences, in understanding women's dating violence victimization.

In addition, the results provided only limited support for the legitimation explanation. The women's experience of corporal punishment and child sexual abuse affected physical assault only indirectly, and these indirect effects did not reach statistical significance. As discussed above, although corporal punishment and child sexual abuse had significant direct effects on sexual coercion, child sexual abuse positively influenced sexual coercion only through antisocial personality.

It is important, however, to note that a limitation of the present study is its small sample size. It is possible that the aforementioned insignificant indirect effects would have reached statistical significance in a larger sample. Indeed, research has shown that corporal punishment increases antisocial behaviour (Grogan-Kaylor, 2004; Straus, Sugarman, \& Giles-Sims, 1997) and antisocial personality disorder has been identified as a mediator between childhood exposure and partner violence (White \& Widom, 2003). Had these indirect effects been significant in the present study, more credence would have been lent 
to the legitimation explanation. Even then, however, there would not be full support for the legitimation explanation as articulated by Simons et al. (1998) in the sense that it must be combined with insights from the criminological perspective to provide an understanding of women's likelihood of physical assault victimization by a dating partner.

Finally, there was no evidence in the present study for the observational learning explanation. Exposure to corporal punishment was clearly not the strongest predictor of the sampled women's dating violence victimization, and it certainly was not the only influence as the observational learning approach had suggested would be the case. Simons et al. (1998) argued that social learning theory required a perceived positive effect of the violence. However, elsewhere it has been argued that learning can take place without positive consequences (Arriaga \& Foshee, 2004; Bandura, 1986). The results of the present study were clearly consistent with the latter view.

In addition to its small sample size, this study was limited in terms of the measures that were employed. Although it represents a major advance in the measurement of family violence, the PRP is preliminary and is in the process of being psychometrically evaluated as more data are collected using this instrument (Straus, Hamby, et al., 1999). On the basis of a preliminary analysis, the validity and reliability of the PRP appear promising (Straus \& Mouradian, 1999). Nevertheless, the measures from the PRP employed in this study may have limited the effects of the independent variables on dating violence victimization. As well, the results are limited to constructs as operationalized by the CTS2 (for a review see Archer, 1999; Sev'er, 2002).

Bearing in mind the aforementioned caveats, future research needs to replicate the present study with a larger sample to further refine our understanding of the intergenerational transmission of women's victimization in dating violence. As well, it would be interesting to determine if there are any cross-cultural variations in the impact of parental behaviours on women's victimization by a dating partner. Future research should also study male victimization in dating violence for a more complete understanding of the specific influence of intergenerational transmission on dating violence.

\section{CONCLUSION}

On the basis of the present investigation it was concluded that intergenerational transmission played a role in women's victimization in dating violence. In harmony with previous research on perpetration, it appeared that multiple modes of transmission influenced women's victimization by a dating partner. However, the results of this investigation suggested that the particular modes of transmission were different when the influence of parental behaviours on women's dating violence victimization was examined.

Elements of the imitation, criminological, and legitimation explanations contributed to understanding women's dating violence victimization. Moreover, the manner in which these elements operated depended upon the form of dating violence under investigation. This study was consistent with previous research in finding that antisocial personality intervened in the relationship between childhood socialization and adult violence. It was unique in its examination of women's exposure and their subsequent victimization and, therefore, in its finding that antisocial personality was also an important intervening variable in the link between women's exposure to family of origin violence and their subsequent dating violence victimization. It has been suggested that antisocial personality may be the key characteristic in understanding the intergenerational transmission of men's violence (Barnett, Miller-Perrin, \& Perrin, 1997). While antisocial personality had an 
important influence on women's victimization in dating violence, antisocial personality was neither the only nor the most influential pathway between exposure to family of origin violence and dating violence victimization. To be sure, the results of this research suggested that, although many other factors come into play, as a mode of intergenerational transmission witnessing inter-parental violence can have a particularly strong impact on women's likelihood of experiencing dating violence.

Interventions to prevent dating violence should not overlook initiatives designed to deal with the impact on women of having witnessed violence in their family of origin. It has been estimated that in $37 \%$ of spousal violence cases in Canada children witness the violence (Dauvergne \& Johnson, 2001). However, this estimate is based on parents' reports. When children self-report exposure the figure is much higher, suggesting that parents underestimate their children's exposure (Barnett et al., 1997). This research added to the existing body of knowledge which suggests that participants in inter-parental violence, their children who witness the violence, child and family services workers, clinicians, policymakers, and other stakeholders need to be educated about the full impact of witnessing inter-parental violence on the future developmental health of children so that more action will be taken to stop the cycle.

\section{NOTES}

1. One of the respondents included in the study reported being in a lesbian dating relationship.

2. Since the data that resulted from the scales are ordinal, for each scale used in the present study the Spearman's and Pearson's correlation coefficients with physical assault were calculated and compared using a test of proportions (Blalock, 1979). All of these analyses showed that the Pearson's correlation coefficients were not significantly different from the Spearman's Rho coefficients $(p<.05)$. Thus, it was concluded that the ordinal data behaved like interval data and were deemed appropriate for use in the multivariate analyses.

3. For the purpose of descriptive analyses, the remaining scale variables were recoded into the categories of high, moderate, and low. The low category includes all values that are more than one standard deviation below the mean. The moderate category includes all values that fall between one standard deviation below and above the mean. The high category includes all values that are more than one standard deviation above the mean.

4. Some of the variables in the LISREL analysis are dichotomous. Past research has shown that it is acceptable to conduct an observed variable path analysis with dichotomous variables. Readers interested in the use of dichotomous variables in LISREL are advised to refer to Hayduk (1987).

5. Incidence refers to the mean frequency among those who were victimized. For further elaboration on definitions of incidence see Brownridge \& Halli (1999).

\section{RÉSUMÉ}

On a examiné l'influence des différents modes de transmission entre les générations, lorsqu'il est question des expériences féminines concernant l'assaut physique et la coercition sexuelle dans les relations amoureuses, avec un groupe de 120 participantes (étudiantes de 3 universités manitobaines). La violence était fréquente : $26.9 \%$ de femmes ont été victimes d'assaut physique. Parmi ces femmes, $41 \%$ ont été blessés. En plus, 36.4\% de l'échantillon ont souffert la coercition sexuelle. La transmission entre les générations a joué un rôle en produisant cette victimisation chez les femmes. Le mode le plus important de transmission entre les générations était l'imitation. Ceci suggère que la violence entre les parents doit être adressée pour améliorer le développement et la santé mentale des enfants qui observent la violence. 


\section{REFERENCES}

American Psychiatric Association. (1994). Diagnostic and statistical manual of mental disorders (4th ed.). Washington, DC: Author.

Archer, J. (1999). Assessment of the reliability of the conflict tactics scales: A metaanalytic review. Journal of Interpersonal Violence, 14(12), 1263-1289.

Arriaga, X.B., \& Foshee, V.A. (2004). Adolescent dating violence: Do adolescents follow in their friends', or their parents', footsteps? Journal of Interpersonal Violence, 19(2), 162-184.

Bandura, A. (1977). Social learning theory. New York: General Learning.

Bandura, A. (1986). The social foundations of thought and action: A social cognitive theory. Englewood Cliffs, NJ: Prentice Hall.

Barnes, G.E., Greenwood, L., \& Sommer, R. (1991). Courtship violence in a Canadian sample of male college students. Family Relations, 40, 37-44.

Barnett, O.W., Miller-Perrin, C.L., \& Perrin, R.D. (1997). Family violence across the lifespan: An introduction. Thousand Oaks, CA: Sage.

Blalock, H.M. (1979). Social statistics (Revised 2nd ed.). New York: McGraw-Hill.

Brownridge, D.A. (2004). Understanding women's heightened risk of violence in commonlaw unions: Revisiting the selection and relationship hypotheses. Violence Against Women, 10(6), 626-651.

Brownridge, D.A., \& Halli, S.S. (1999). Measuring family violence: The conceptualization and utilization of prevalence and incidence rates. Journal of Family Violence, 14(4), 333-350.

Cappell, C., \& Heiner, R.B. (1990). The intergenerational transmission of family aggression. Journal of Family Violence, 5(2), 135-152.

Dauvergne, M., and Johnson, H. (2001). Children witnessing family violence. In C. Trainor and K. Mihorean (Eds.), Family violence in Canada: A statistical profile 2001 (pp. 1925). Ottawa: Minister of Industry, 2001.

DeKeseredy, W., \& Kelly, K. (1993). The incidence and prevalence of woman abuse in Canadian university and college dating relationships. Canadian Journal of Sociology, 18(2), 137-159.

DeMaris, A. (1987). The efficacy of a spouse abuse model in accounting for courtship violence. Journal of Family Issues, 8, 291-305.

Forbes, G.B., \& Adams-Curtis, L.E. (2001). Experiences with sexual coercion in college males and females. Journal of Interpersonal Violence, 16(9), 865-889.

Grogan-Kaylor, A. (2004). The effect of corporal punishment on antisocial behavior in children. Social Work Research, 28(3), 153-162.

Gwartney-Gibbs, P.A., Stockard, J., \& Bohmer, S. (1987). Learning courtship aggression: The influence of parents, peers, and personal experiences. Family Relations, 36, 276282.

Hayduk, L.A. (1987). Structural equation modeling with LISREL. Baltimore: The Johns Hopkins University Press.

Hines, D.A., \& Saudino, K.J. (2002). Intergenerational transmission of intimate partner violence: A behavioral genetic perspective. Trauma, Violence and Abuse, 3(3), 210-225.

Jackson, S.M. (1999). Issues in the dating violence research: A review of the literature. Aggression and Violent Behavior, 4(2), 233-247.

Jankowski, M.K., Leitenberg, H., Henning, K., \& Coffey, P. (1999). Intergenerational transmission of dating aggression as a function of witnessing only same sex parents vs. 
opposite sex parents vs. both parents as perpetrators of domestic violence. Journal of Family Violence, 14(3), 267-279.

Johnson, H. (1996). Dangerous domains: Violence against women in Canada. Scarborough, ON: Nelson Canada.

Kalmuss, D. (1984). The intergenerational transmission of marital aggression. Journal of Marriage and the Family, 46, 11-19.

Kaufman, J., \& Zigler, E. (1987). Do abused children become abusive parents? American Journal of Orthopsychiatry, 57(2), 186-192.

Koss, M.P., \& Dinero, T.E. (1989). Discriminant analysis of risk factors for sexual victimization. Family Relations, 57, 242-250.

Laner, M.R., \& Thompson, J. (1982). Abuse and aggression in courting couples. Deviant Behavior, 3, 229-244.

Lavoie, F., Hébert, M., Tremblay, R., Vitaro, F., Vézina, L., \& McDuff, P. (2002). History of family dysfunction and perpetration of dating violence by adolescent boys: A longitudinal study. Journal of Adolescent Health, 30, 375-383.

Malik, S., Sorenson, S.B., \& Aneshensel, C.S. (1997). Community and dating violence among adolescents: Perpetration and victimization. Journal of Adolescent Health, 21(5), 291-302.

Marshall, L.L., \& Rose, P. (1988). Family of origin violence and courtship abuse. Journal of Counseling and Development, 66, 414-418.

O'Keefe, M. (1998). Factors mediating the link between witnessing interparental violence and dating violence. Journal of Family Violence, 13(1), 39-57.

Pedersen, P., \& Thomas, C.D. (1992). Prevalence and correlates of dating violence in a Canadian university sample. Canadian Journal of Behavioural Science, 24(4), 490-501.

Riggs, D.S., Caulfield, M.B., \& Street, A.E. (2000). Risk for domestic violence: Factors associated with perpetration and victimization. Journal of Clinical Psychology, 56, 1289-1316.

Romano, E., \& De Luca, R.V. (1997). Exploring the relationship between childhood sexual abuse and adult sexual perpetration. Journal of Family Violence, 12(1), 85-98.

Schmitt, N. (1996). Uses and abuses of coefficient alpha. Psychological Assessment, 8(4), 350-353.

Sev'er, A. (2002). Fleeing the house of horrors: Women who have left abusive partners. Toronto: University of Toronto Press.

Sharpe, D., \& Taylor, J.K. (1999). An examination of variables from a socialdevelopmental model to explain physical and psychological dating violence. Canadian Journal of Behavioural Science, 31(3), 165-175.

Sigelman, C.K., Berry, C.J., \& Wiles, K. (1984). Violence in college students' dating relationships. Journal of Applied Social Psychology, 5(6), 530-548.

Simonelli, C.J., Mullis, T., Elliott, A.N., \& Pierce, T.W. (2002). Abuse by siblings and subsequent experiences of violence within the dating relationship. Journal of Interpersonal Violence, 17(2), 103-121.

Simons, R.L., Lin, K.-H., \& Gordon, L.C. (1998). Socialization in the family of origin and male dating violence: A prospective study. Journal of Marriage and the Family, 60, 467-478.

Smith, M.D. (1994). Enhancing the quality of survey data on violence against women: A feminist approach. Gender and Society, 8(1), 109-127.

Stets, J.E., \& Pirog-Good, M.A. (1987). Violence in dating relationships. Social Psychological Quarterly, 50, 237-246. 
Straus, M.A. (1990). The Conflict Tactics Scales and its critics: An evaluation and new data on validity and reliability. In M.A. Straus \& R.J. Gelles (Eds.), Physical violence in American families: Risk factors and adaptations to violence in 8,145 families (pp. 4973). New Brunswick, NJ: Transaction.

Straus, M.A., Aldrighi, T., Alvarez, S.D., Atan, A., Boeckmann, I., Sieber, C., et al. (2004). Prevalence of violence against dating partners by male and female university students worldwide. Violence Against Women, 10(7), 790-811.

Straus, M.A., Hamby, S.L., Boney-McCoy, S., \& Sugarman, D.B. (1996). The revised Conflict Tactics Scales (CTS2): Development and preliminary psychometric data. Journal of Family Issues, 17(3), 283-316.

Straus, M.A., Hamby, S.L., Boney-McCoy, S., \& Sugarman, D.B. (1999). The Personal and Relationships Profile (PRP). Durham, NH: University of New Hampshire, Family Research Laboratory.

Straus, M.A., \& Mouradian, V.E. (1999). Preliminary psychometric data for the Personal and Relationships Profile (PRP): A multi-scale tool for clinical screening and research on partner violence. Paper presented at the meeting of the American Society of Criminology, Toronto.

Straus, M.A., Sugarman, D.B., \& Giles-Sims, J. (1997). Spanking by parents and subsequent antisocial behavior of children. Archives of Pediatrics and Adolescent Medicine, 151, 761-767.

White, H.R., \& Widom, C.S. (2003). Intimate partner violence among abused and neglected children in young adulthood: The mediating effects of early aggression, antisocial personality, hostility and alcohol problems. Aggressive Behavior, 29, 332345.

Widom, C.S. (1989). Does violence beget violence? A critical examination of the literature. Psychological Bulletin, 106(1), 3-28. 